\title{
Meneguhkan Pendekatan Neurolinguistik dalam Pembelajaran: Studi Kasus pada Pembelajaran Bahasa Arab Madrasah Aliyah
}

\author{
Mohammad Jailani*, Wantini, Suyadi, \& Betty Mauli Rosa Bustam
}

\author{
Magister Pendidikan Agama Islam, Universitas Ahmad Dahlan Yogyakarta, Indonesia \\ Jl. Pramuka No.42, Pandeyan, Kec. Umbulharjo, Kota Yogyakarta, \\ Daerah Istimewa Yogyakarta 55161 \\ Email: mohammad2007052014@webmail.uad.ac.id
}

\begin{abstract}
This study aims to analyze Arabic learning with a neurolinguistic approach at Madrasah Aliyah. Students have difficulty understanding, memorizing, and practicing Arabic mufrodat and muhadatsah. This research uses a case study approach, with the informants being the head of the madrasa, the representative of the curriculum, and the Arabic language teacher. Data were collected by observation and in-depth interviews. The results showed that the neurolinguistic approach helps students understand Arabic learning through brain function in language. The optimization of the nervous system in language is able to integrate the role of the brain in the ability to learn Arabic in cognitive, affective, and psychometric aspects. Neurolinguistics makes it easier for students to understand mufrodat, namely in terms of qiro'ah, kitabah, istima', and kalam skills. Thus, the neurolinguistic approach as an alternative to learning Arabic can increase the potential of students who rely on their brains. The neurolinguistic approach will have broad implications for the discourse on the development of Arabic learning during the 4.0 industrial revolution.
\end{abstract}

Keywords: Arabic language, neurolinguistic approach, learners.

\begin{abstract}
Abstrak: Penelitian ini bertujuan untuk menganalisis pembelajaran bahasa Arab dengan pendekatan neurolinguistik di madrasah aliyah. Peserta didik kesulitan dalam memahami, menghafal, dan mempraktekkan mufrodat dan muhadatsah Bahasa Arab. Penelitian ini menggunakan pendekatan studi kasus, dengan informan adalah kepala madrasah, wakil bidang kurikulum, dan guru Bahasa Arab. Data dikumpulkan dengan observasi dan wawancara mendalam. Hasil penelitian menunjukkan bahwa pendekatan neurolinguistik membantu peserta didik dalam memahami pembelajaran Bahasa Arab melalui fungsi otak pada bahasa. Optimalisasi sistem saraf pada bahasa mampu mengintegrasikan peran otak terhadap kemampuan belajar Bahasa Arab dalam aspek kognitf, afektif, dan psikomotorik. Pendekatan neurolinguistik memudahkan peserta didik dalam memahami mufrodat yakni dalam hal keterampilan qiro'ah, kitabah, istima', dan kalam. Dengan demikian, pendekatan neurolinguistik sebagai alternatif pembelajaran Bahasa Arab dapat meningkatkan potensi peserta didik yang bertumpu pada otaknya. Pendekatan neurolinguistik akan berimplikasi luas terhadap diskursus pengembangan pembelajaran Bahasa Arab di masa revolusi industri 4.0.
\end{abstract}

Kata Kunci: Bahasa Arab, pendekatan neurolinguistik, peserta didik.

Jurnal Pendidikan Agama Islam Al-Thariqah Vol. 6, No. 1, Januari - Juni 2021 Received : 23 Desember 2020; Accepted : 21 Juni 2021; Published : 30 Juni 2021

*Corresponding Author : mohammad2007052014@webmail.uad.ac.id 


\section{PENDAHULUAN}

Pendekatan pembalajaran sangat penting dimiliki oleh guru karena menjadi kunci sukses dalam mempermudah peserta didik untuk pembelajaran yang berkualitas. Bangunan literatur menunjukkan bahwa guru yang menguasai pendekatan dalam pembelajaran dapat mempermudah peserta didik dalam pembelajaran. Guru mudah dalam mengajar dan peserta didik senang dalam belajar (Tambak, and Sukenti, 2020). Penguasaan guru terhadap pendekatan pembelajaran dapat mengembangkan kualitas mengajar dan penguasaan bahan belajar peserta didik pun dapat terapai secara maksimal (Hamzah, et al. 2020; Tambak, Ahmad, and Sukenti, 2020).

Majunya teknologi informasi secara pesat mempengaruhi pembelajaran dalam proses, pengembangan, dan evaluasi, karena sinkronisasi pembelajaran dengan kemampuan otak peserta didik terkadang masih terabaikan. Hal ini terlihat secara khusus dalam pembelajaran Bahasa Arab sebagai mata pelajaran (muatan lokal) yang oleh siswa banyak tidak minati disebabkan sulit untuk dipahami. Pemahaman dari aspek percakapan (muhadatsah bilmufradat) yang disebut belajar aktif, ataupun secara gramatikal (qowa'idul arabiyah) yang dikenal dengan pembelajaran pasif, masih menjadi persoalan krusial terjadi pada peserta didik madrasah. Padahal sangat penting sebuah pendekatan untuk pengembangan pembelajaran yang baik dan menarik agar peserta didik dapat belajar dengan menyenangkan, terutama dalam pembelajaran Bahasa Arab (Vogel, Goffin, and Ansari, 2015).

Sejauh ini, penelitian tentang pembelajaran Bahasa Arab dengan berbagai pendekatan pembelajaran untuk mempermudah siswa dalam belajar, telah banyak diteliti dalam dunia pendidikan. Penelitian Sitohang (2019a) tentang pengembangan pemrograman neurolingustik berbantuan literasi informasi dalam pembelajaran pidato siswa. Ia menyatakan dalam hasil penelitiannya bahwa metode NLP berbantuan literasi informasi dapat mengatasi problematika dan meningkatkan respon guru terhadap penggunaan metode NLP berbantuan literasi informasi. Hasil uji menunjukkan dengan uji statistika non parametrik menunjukkan bahwa terdapat perbedaan yang signifikan. Respon guru menyatakan metode NLP berbantuan literasi informasi membantu siswa meningkatkan percaya diri, membangun motivasi, dan memudahkan mereka mencapai tujuan pembelajaran. Dengan demikian metode neurolinguistik programing mampu memudahkan siswa dalam merespons materi pembelajaran Bahasa Indonesia. Penelitian ini lebih mengarah kepada pendekatan penggunaan neurolingiustik pada pembelajaran Bahasa Indonesia dengan pemograman NLP. Penelitian serupa juga diteliti oleh Hilmi (2017), dimana dalam artikel ilmiahnya fokus pada sistem pembelajaran (al-qawa' id alsharfiyah) di Indonesia dalam perspektif neurolinguistik. Penelitian ini lebih mengarah kepada morfologi Arab atau bentuk kata. Tinjauan penelitian mengarah kepada quwa'id as-sharfiiyah dalam budaya belajar baik di sekolah formal maupun di pondok pesantren. Namun dalam closing penelitiannya, ia menegaskan jika pembelajaran quwa'id as-sharfiyyah lebih relevan dalam pembelajaran Bahasa Arab khususnya pada bab quwa'id (gramatikal) dengan pendekatan neurolinguistik.

Dengan demikian pembelajaran Bahasa Arab masih menjadi persoalan krusial di dunia pendidikan. Permasalahan ini juga terjadi di Madrasah Aliyah Itmamunnajah. Berdasarkan hasil wawancara bersama pendidik dan wali kelas, dimana peserta didik mengalami kesulitan dalam merespons pembelajaran Bahasa Arab yang yang disampaikan oleh pendidik. Belum adanya pendampingan secara dan fokus pendidik dengan metode pembelajaran yang baik. Di satu sisi peserta didik belum bisa membaca AlQur'an dan belum adanya pembelajaran yang relevan dengan cara berfikir dan belajar peserta didik, sekedar contoh pembelajaran cara konvensional berbasis modul atau bahan ajar biasa. Selama ini 
pembelajaran Bahasa Arab yang dikembangkan lebih mengarah pada sistem pondok pesantren. Peserta didik ditekankan pada hafalan mufrodat. Sesuai hasil survey pendahuluan "pembelajaran yang dikembangkan di MA Itmamunnajah adalah pembelajaran berbasis pondok pesantren. Peserta didik diarahkan kepada pembelajaran berbasis pondok pesantren, karena pada dasarnya Madrasah Aliyah Itmamunanjah adalah dekat dengan pondok secara otomatis lembanga ini dipengaruhi dan diarahkan ke pondok pesantren. Dasar kebiasaan dan pendidikan yang ditekankan adalah pondok pesantren, bahkan ketua Yayasan dan pengjar yang ada di MA Itmamunnajah adalah alumni dan pengajar dari pondok pesantren. Pembelajaran di MA Itmamunnajah lebih diarahkan kepada pondok pesantren dan ciri khas yang ditonjolkan atau sebagai andalan pembelajarannya adalah pembacaan kitab kuning. Target pembelajaran yang ditetapkan oleh madrasah adalah peserta didik kelas X (sepuluh) harus mampu membaca kitab kuning yaitu level dasar kitab jurumiah. Permasalahan yang ada jika peserta didik yang lulusan dari sekolah umum di MA Itmamunnajah secara otomatis ketinggalan dalam menyesuaikan materi Bahasa Arab yang disampaikan oleh guru/pendidik. Selama ini pembelajaran Bahasa Arab identik dengan teknik konvensional yaitu ceramah, artinya peserta didik dibranding pembelajarannya membaca, menulis, dan dijelaskan terkait materi yang diajarkan.

Untuk mengatasi permasalahan tersebut, maka dibutuhkan pendekatan baru dalam pembelajaran Bahasa Arab di madrasah aliyah, dengan pengembangan pembelajaran baru yang mana sudah fenomenal dalam masa terkini yaitu pendekatan neurolinguistik. Pendekatan neurolinguistik merupakan pembelajaran yang mendesain pada sistem otak dan bahasa (neuro dan linguistic) (Hilmi, 2017). Sistem otak dan fungsi bahasa sangat berkaitan dalam sistem saraf manusia termasuk peserta didik. Otak adalah pusat saraf yang berfungsi sebagai pengendali pikiran dan mekanisme organ tubuh. Diantara fungsinya adalah sebagai pemrosesan bahasa (Jailani, Suyadi, and Djabedi, 2021). Oleh sebab itu peserta didik yang selama ini kurang menarik dalam memahami Bahasa Arab, hal itu disebabkan kurang pekanya rangsangan otak, dan kurang merespon terhadap bahasa. Maka, menjadikan komonikasi bahasanya tidak aktif atau berfungsi. Oleh karenanya penelitian ini fokus membahas pendekatan neurolinguistik dalam pembelajaran yaitu menerapkan rangsangan otak kanan dan kiri (neurologis) dalam pembelajaran bahasa secara eksplesit pada sintaksisnya, (nahwu) (Budianingsih, 2015).

Berdasarkan hal tersebut dapat diinterpretasi bahwa pembelajaran Bahasa Arab penting untuk ditindaklanjuti guna dalam mengembangkan pembelajaran Bahasa Arab. Secara ekplesit di Madrasah Aliyah Itmamunnajah menerapkan nilai-nilai Islam dan pembelajaran kitab al-turats yang otomatis peserta didik lebih dekat dengan pembelajaran agama Islam dan juga Bahasa Arab. Meskipun di MA Itmamunnajah terdapat jurusan sosial atau ilmu pengetahuan sosial, dan akuntansi, namun peserta didik menekankan pada pembelajaran agama Islam terutama Bahasa Arab. Berdasarkan atas hal tersebut dan bukti valid penelitian pendahuluan permasalahan yang terjadi di MA Itmamunnajah, masih terjadi minimnya daya minat belajar bahasa, serta belum ter-aptodate-nya pendekatan pembelajaran yang diterapkan. Maka penelitian ini merupakan hal baru dan belum pernah diteliti dalam dunia pendidikan Islam yaitu pengembangan pembelajaran Bahasa Arab dengan pendekatan neurolinguistik di Madrasah Aliyah Itmamunnajah. Pendekatan neurolinguistik merupakan pengetahuan 
dan analisis ilmu neurosain yang dikenal selama ini yaitu ilmu tentang konsepkonsep otak sebagai pandangan dan tinjauan pembelajaran terhadap siswa di sekolah (Suyadi and Widodo, 2019 Ahmad, Tambak, and Hasanah, 2018).

Maka penelitian ini menganalisis pendekatan neuroinguistik dalam pembelajaran Bahasa Arab. Pendekatan ini mengembangkan kemampuan siswa agar tertarik dan minat dalam belajar Bahasa Arab. Tidak monoton dan merasa jenuh, dan menghindari paradigma bahwa selama ini dianggap sulit belajar Bahasa Arab. Sebenarnya pembelajaran Bahasa Arab sangat mudah untuk dikuasai, sebab berkomonikasi dalam kehidupan seharihari. Pendekatan neurolingiustik berperan penting dalam mengembangkan otak siswa, dan kemampuan berbahasa tinggi. Pendekatan ini mempengaruhi otak peserta didik memberi motivasi belajar berupa motivasi dan kesadaran bahwa pentingnya belajar Bahasa Arab. Bahasa Arab adalah alat verbal yang diaplikasikan untuk berkomonikasi dan menghindari kesalahan dalam bercakap (Iljina, et al. 2017).

Penelitian ini didasarkan pada argumen yang relevan pada masa kini bahwa pendekatan pembelajaran neurolinguistik sangat membantu dan mendukung dalam belajar bahasa arab bagi peserta didik di sekolah. Pendekatan ini mengarahkan kepada kemampuan kognitif, afektif dan psikomotorik peserta didik, secara khusus pada kemampuan bahasa Arab. Sejauh pembelajaran bahasa Arab dalam pendidikan, selama ini kurang menarik terhadap pola fikir dan kegiatan siswa (Jailani, et al. 2021), karena pendekatan yang digunakan lebih mengarah pada pembelajaran metode ceramah, menulis, ataupun lebih banyak pada teori, menyebabkan siswa depresi dan merasa jenuh. Oleh karenanya dalam kacamata penelitian dengan penelitian ini, dan berdasar atas asumsi pada penelitianpenelitian yang terdahulu membuktikan banyak berhasil yaitu pendekatan neurolinguistik dalam pembelajaran
Bahasa Arab. Hal penting nantinya menjadi kekuatan super terhadap implikasi diskursus pendidikan Islam menjadi sebuah temuan baru yag selama ini banyak para ilmuan pendidik belum menelitinya (Beatty-Martínez and Dussias, 2019). Temuan baru ini, tentang pendekatan pembelajaran neurolinguistik, sangat membantu dalam kurikulum pendidikan, dan ter-up to date-nya pembelajaran dan media pembelajaran, para guru lebih inovatif dan kreatif. Karena ada motivasi tersendiri dalam gaya pikirnya, peserta didikpun sangat antusias dalam belajar Bahasa Arab.

Fokus penelitian ini adalah memberikan alternatif dengan strategi pembelajran Bahasa Arab melalui pendekatan neurolinguistik. Sebagaimana untuk mengatasi kesulitankesulitan peserta didik dalam belajar bahasa Arab. Menyesuaikan terhadap apa yang diharapkan oleh peserta didik dan menyesesuaikan dengan cara belajar peserta didik dengan penggunaaan otak kanan dan otak kiri, pembelajaran yang memudahkan dan menyenangkan. Alternatif strategi pembelajaran ini bisa di dukung dengan memanfaatkan terhadap penggunaaan media pembelajaran baik berbasis audio visual ataupun berbasis media yang lain. Pembelajaran bahasa Arab dengan pendekatan neurolinguistik materi yang disampaikan kepada peserta didik berkaitan dengan fungsi otak. Sebagaimana yang telah bergulir dan terkenal ditelingan dan benak peneliti dan akademisi khususnya di basis penelitian yang berkutip pada saintifik dan edukasi.

\section{KONSEP TEORI}

\section{Pendekatan Neurolinguistik dalam Pembelajaran Bahasa Arab}

Neurolinguistik adalah ilmu yang membahas tentang otak berkaitan dengan bahasa. Otak tidak bisa digunakan dalam berucap, karena ada lisan yang sudah bertugas untuk bertindak tutur sedangkan otak adalah sebagai optimalisasi berfikir 
dalam menyampaikan bunyi atau bahasa (Hilmi, 2017). Neurolinguistik merupakan suatu proses pendekatan pembelajaran yang melibatkan organ otak dan alat indra lidah sebagai landasan berfikir dan berkomonikasi dalam rangka mendapatkan hasil yang diharapkan (Sitohang, 2019). Neurolinguistik adalah peran utama dari respon otak bagian kanan dan kiri terhadap sinkronisasi lidah dalam ucapan. Dalam hal ini neurolinguistik merupakan fokus gerak utama otak bagian kanan berkaitan dengan lidah untuk menghasilkan bunyi bahasa secara aktif dan benar (Budianingsih, 2015). Berdasarkan teori tersebut dapaat diinterpretasi bahwa neurolinguistik adalah gabungan dari dua kata antara lain yang pertama berasal dari kata neuro (neurolinguistik) adalah disiplin ilmu yang mempelajari tentang otak beserta fungsi-fungsinya, serta yang kedua adalah berasal dari kata linguistik (language) yaitu ilmu yang membahas tentang bahasa terdari dari (fonologi, sintaksis, morfologi dan, semantic). Jadi dapat dikemukakan bahwa neurolinguistik merupakan ilmu yang mempelajari tentang otak berhubungan dengan bahasa. Melakukan uji pendekatan pembelajaran tergadap siswa melalui rangsangan pada otak bagian kanan dan kiri terhadap bahasa, yang bertujuan nanti agar para siswa bisa melakukan mudah memahami sesuai kesadaran dan kecerdasan otaknya (Jailani, Suyadi, and Djabedi, 2021). Selama ini para siswa itu masih kurang mampu menguasai Bahasa Arab, dan dikhawatirkan otak tidak bisa merespon atau menerima informasi dari guru terhadap fungsi (nasyiyah) lobus frontalnya (Ferretti, et al. 2020). Hal ini kemudian berfungsi sebagai pusat kendali otak, dan memory yang merefleksi terhadap komonikasi (tuturan bahasa).

Berdasarkan telaah lieteratur riveiw di atas maka dapat ditegaskan bahwa peran penting dari seorang pendidik atau guru di sekolah sangat diperlukan dalam proses belajar untuk mengembangkan kemampuan otak peserta didik (Jailani, et al. 2021). Di sisi lain dapat digambarkan bahwa neurolinguistik adalah gabungan peran dari sebuah otak yang saling berhubungan dengan aspek bahasa pada diri peserta didik (Suyadi, Nuryana, and Fauzi, 2020). Kajian neurolinguistik adalah kajian bahasa yang fokus pada peran otak dalam berujar dan beraktivitas bahasa pada umumnya (Ferretti, et al. 2020). Dalam kajian neurolinguistik terdapat pemikiran bahwa peserta didik dalam merespons informasi yang didapatkan dapat diolah oleh otak kiri dan disimpan dalam otak kanan (Ferretti, et al. 2020).

Kaidah neurolinguistik menjelaskan bahwa optimalisasi tingkat kebahasaan manusia dipengaruhi oleh beberapa kuat kualitas dan kuantitas saraf manusia dalam mentransfer dan mengolah informasi itu dianggap tidak memiliki makna dalma hidup peserta didik, sehingga infomrasi tersebut tidak akan merespon lama di dalam saraf (BeattyMartínez, and Dussias, 2019). Otak manusia pada dasarnya terbagi dua bagian yaitu otak kiri dan otak kanan, bahkan dalam pengetahuan terkini memposisikan belahan otak tengah sebagai sebagai penengah dan pengendali dua belah yang lainnya. Otak kiri dikenal sebagai otak bahasa dan matematis, sementara otak kanan dikenal sebagai otak seni dan warna. Dua otak tersebut memiliki kecenderungan yang berbeda, maka dari itu pembelajaran bahasa terkhusus Bahasa Arab betul-betul memperhatikannya (Jailani, Suyadi, and Djabedi, 2021). Mengingat hal itu pembelajaran Bahasa Arab sangat berkaitan dengan otak kanan dan otak kiri. Saling berhubungan antara sinkronisasi otak kanan dan otak kiri. Dijelaskan dalam literatur di atas ternyata bagian-bagian otak memiliki fungsin tersendiri dan tugas tersendiri. 


\section{Pentingnya Mengenalkan Metode Pembelajaran Bahasa Arab yang Digunakan}

Hal ini sangat efisien bagi pendidik untuk mengerti prinsip, metode, dan tujuan belajar Bahasa Arab. Secara mendasar diketahui bahwa metode pembelajaran Bahasa Arab adalah sekumpulan teknik yang digunakan untuk mengarahkan proses kegiatan pembelajaran ke arah tujuan pembelajaran sebagaimana sebelumnya sudah ditetapkan oleh kurikulum pendidikan (Winarto, Syahid, and Saguni 2020; Tambak, 2010). Mengenai metode yang perlu disampaikan kepada siswa diantaranya: tujuan pembelajaran Bahasa Arab, tipe golongan masyarakat yang seperti apa siswa itu habitatnya, tingkatan pembelajaran dalam bahasa Arab (dari pemula sampai tingkat lanjut), karakterisitik siswa itu sendiri dan dialek atau penguasaan dalam materi. "Semisal jika di daerah Madura itu masih kental dengan dialeknya, kalau sudah masuk diranah dialek agak sulit untuk membiasakan dalam dialek seperti biasanya dalam bahasa Arab" (2). Biasanya jika di tingkat Madarasah Aliyah itu sudah lumayan bisa dalam tata bahasa atau (quwa'id)nya, sementara yang perlu ditekankan adalah praktik menyampaikannya secara aktif (billugeh Al 'Arobiyah) (Mahmudah, 2020).

Konsep neurlonguistik tidak terlepas dari pembahasan anatomi otak, dua bagian otak ikut andil dalam mengolah informasi yang berhubungan dengan bahasa. Terlebih pada Bahasa Arab yang dipelajari oleh peserta didik akan selalu tersimpan dalam memori otak. Hanya saja kekuatan memori otak tergantung pada optimalisasi, apabila melibatkan otak kanan secara otomatis akan bertahan lebih lama (Ferretti, et al. 2020). Kajian neurolinguistik kini lebih banyak menajdi pokok bahasan di basis penelitian bahkan dalam perbincangan di seluruh dunia dengan berbagai modif cara beljar yang bisa merangsang otak untuk belajar dengan maksimal. Ketercapaian belajar tergantung bagaimana otak dapat dioptimalisasikan dengan baik tanpa mengganggu kealamiahannya dalam menyerap, mengolah, menyimpan dan merealisasikannya (Iljina, et al. 2017). Bahasa dipelajari oleh tiap manusia secara bertahap, ya'ni sejak bayi berusia 6-8 minggu mulai mendekat yang berupa pengucapan bunyi-bunyi yang belum bisa diidentifikasi secara konkrit. Kemudian pada usia 6 bulan, anak mulai bisa mengeluarkan bunyi per-huruf dengan menuturkan bunyi yang berupa suku kata, lalu pada usia satu tahun anak bisa menuturkan bunyi secara sempurna, sekedar contoh penyampaian kata burung yang dapat dilafalkan dengan kata rung. Pada perkembangan selanjutnya, anak mulai berujar dengan satu kata jelas (one word utterance), sementara itu mendekati usia dua tahun barulah anak mulai mampu berujar dua kata (two words utterance) sampai usia 4-5 tahun yang dapat berkomonikasi dengan lancar. Pertambahan usia manusia sejak bayi terus mengalami peningkatan otak dalam memproduksi bahsa. Perkembangan tersebut ditentukan seberapa peran fisologis dan biologis anak dalam menggerakkan organ bicara dengan baik. Apabila biologis anak tidak berfungsi dengan baik, maka dipastikan produksi bahasanya juga akan mengalami gangguan (Hilmi, 2017).

Kemampuan berujar anak secara umum bersifat relative bergantung kondisi dan factor biologis yang berbedabeda. Namun pada dasarnya urutan pemerolehan bahasa anak sama mulai dari dekutan hingga ke celotehan. Kualitas produksi bahasa anak menunjukkan peran otak yang baik dalam berfikir. Pada dasarnya otak kiri manusia diciptakan untuk menghasilkan bahasa yang akan diserap secara bertahap melalui organ bicara. Kemampuan otak untuk mengenali makna berbeda di dalam struktur kalimat bisa terjadi, karena wilayah Broca dan Wrnicke membangun jejaring yang berhubungan yang bisa memahami perbedaan antara "anjing mengejar 
kucing" dan "kucing mengejar anjing". Dalam studi FMRI mendapatkan wilayah Broca dan Wrnicke bekerja sama untuk menentukan apakah perubahan dalam perubahan sintaks atau semantics menghasilkan perubahan maka dalam bahasa Arab (Hilmi, 2020).

Ruang linkup neurolinguistic merupakan gabungan objek linguistic dan neurosains dengan menintikberatkan kajiannya pada bidang neurosains (optimalisasi otak). Neurosains menjelaskan bahasa dilihat dari aspek neurosains dan sejauh yang dapat dipikirkan oleh manusia (Schiller 2020). Neurolinguistic merupakan ilmu lnguistik terapan yang membahas fenomena berbahasa atau hubungan bahasa dengan akal, yang membahas kaitan bahasa dengan aspek eksternal bahasa. Neurolinguistic sangat erat kaitannya dengan pembelajaran bahasa, karena disamping ruang lingkup pembahasan neurolinguistic mencakup pembahasan fenomena pemerolehan dan pembelajaran bahasa, ia uga membahas bagaimana pembelajaran bahasa yang baik (Jundi and Yasin, 2020). Begitupun pembelajaran bahasa Arab, yang meliputi prinsip Pendidikan, prinsip neurosains, dan prinsip linguistic, dimana ketiga prinsip ini merupaka titik temu antara linguistic dan pembelajaran bahasa (Ismail, 2013). Di sini tampak titik temu neurolinguisitk dengan pembelajaran bahasa Arab berdasarkan prinsip pendidikan, neurosains, dan linguistik.

Pandangan tentang dikotomi tingkat kesulitan sebagaimana disebutkan sebelum menjadi dasar kurang efektifnya menumbuhkan motivasi belajar peserta didik serta kurangnya penguatan sistem pembelajaran yang efektif. Kondisi ini akan mendorng peserta didik untuk mengabaikan ilmu Bahasa Arab baik mufrodat maupun quwa'id. Oleh karenanya seharusnya guru mampu memilih metode yang tepat dan mengaplikasikannya dengan baik sesuai dengan karakteristik ilmu Bahasa Arab serta relevan dengan kondisi peserta didik yang membutuhkan belajar secara praktis.

\section{METODE PENELITIAN}

Penelitian ini dilakukan di Madrasah Aliyah Itmamunnajah, Pasongsongan, Sumenep, Madura. Pemilihan madrasah sebagai objek penelitian dengan asumsi bahwa pola pembelajaran Bahasa Arab yang ada di MA Itmamunnajah memenuhi kriteria objek penelitian. Penting dilakukan penelitian terkait pengembangan pembelajaran dengan pendakatan neurolinguistic. Sejalan dengan survey penelitian pendahuluan ada persoalan yang ditindaklanjuti dalam mengatasi kasus pembelajaran di MA Itmamunnajah, yaitu sulitnya belajar bahasa Arab sebagai mata pelajaran yang dikembangkan di madrasah.

Pendekatan penelitian yang digunakan dalam penelitian ini adalah pendekatan studi kasus. Alasan penggunaan metode ini karena menganalisis pembelajaran Bahasa Arab yang implementasikan di MA Itmamunnajah dengan pendekatan neurolinguistic. Informan penelitian ini adalah kepala madrasah, waka kurikulum, guru bahasa Arab, dan wali kelas. Dari subjek penelitian tersebut diharapkan memperoleh data yang lengkap dan valid mengenai pembelajaran bahasa Arab yang ada di MA Itmamunnajah.

Teknik pengumpulan data dilakukan dengan menggunakan; Pertama, wawancara mendalam dengan berpedoman pada interview guide dan bersifat tidak struktur. Wawancara merupakan data primer dalam penelitian ini. Wawancara dimaksudkan untuk memperoleh data dengan jalan mengajukan pertanyaan-pertanyaan tentang segala sesuatu kepada informan mengenai pembelajaran Bahasa Arab di MA Itmamunnjah. Alat yang digunakan yaitu instrumen wawancara dan observasi melaui alat komonikasi (hanpond) dengan pedoman wawancara. Penelitian ini memanfaatkan secara holistik dan 
universal dari sumber data primer dan sekunder serta informasi observasi. Wawancara dilakukan untuk mengeksplor pendekatan neurolinguistik dalam proses pembelajaran Bahasa Arab di MA Itmamunnajah Pasongsongan. Informan yang diwawancarai adalah kepala madrasah, waka kurikulum, guru dan peserta didik. Kedua, observasi, dilakukan untuk mendapatkan kondisi obyektif di madrasah MA Itmamunnajah Pasongsongan, Sumenep. Observasi yang dilaksanakan bersifat formal maupun tidak formal.

Adapun teknik analisis data, peneliti menggunakan teori yang dikemukakan oleh Miles dan Huberman bahwa proses analisis data terbagi menjadi tiga tahapan yaitu reduksi data, penyajian data, dan penarikan kesimpulan dan verifikasi data (Sugiyono, 2015). Peneliti mereduksi data dengan merangkum data yang diperoleh dan memilih data-data pokok yang diperlukan. Sehingga memperoleh data yang lebih jelas dan memudahkan untuk memperoleh data-data selanjutnya. Kemudian peneliti menyajikan data-data yang telah diperoleh, menggabungkan data data yang telah disusun sehingga memungkinkan untuk ditarik kesimpulan dan memverifikasinya.

\section{HASIL DAN PEMBAHASAN}

Hasil penelitian ini, disajikan berdasarkan tema-tema yang dihasilkan selama proses penelitian berjalan melakukan pengumpulan data di MA Itmamunnajah sekaligus menjawab variabel rumusan masalah pertanyaan diatas. Berdasarkan analisis data ditemukan beberapa subtansi tema utama yang mempengaruhi hasil penelitian ini yaitu:

\section{Pembelajaran Bahasa Arab di Madrasah Aliyah}

Berdasar pada wawancara dari pimpinan madrasah dan wakil bidang kurikulum, "bahwa Madrasah Aliyah Itmamunnajah sudah menerapkan kurikum 2013 dan telah menerapkan silabus pembelajaran sesuai aturan dari pemerintah. Guru ditekankan mendorong siswanya lebih mandiri untuk aktif belajar. Artinya dari (teacher centered) menuju (learner centered). Kurikulum Bahasa Arab mempunyai prinsip dasar dalam merancang empat landasan utuk diterapkan dalam keterampilan bahasa. Diantara bagian-bagian penting dalam dasar itu adalah tujuan pembelajaran, materi bahan ajar, metode pembelajaran, aktitivitas pembelajaran, media pembelajaran, dan penilaian pembelajaran. Dimana guru-guru yang di Madrasah Aliyah Itmamunnajah sudah memenuhi persayarakatan pokok dasar itu. Akan tetapi dari hal itu, diketahui tetapi masih banyak kendala dalam pembelajaran dikelas" (2).

Realitas yang ada pada umumnya konsep kurikulum yang menjalar di kalangan pendidikan lebih mendahulukan kurikulum sebagai subjek pendidikan. Pandangan ini melihat ilmu pengetahuan lebih mendominasi kepada keseluruhan proses pendidikan. Hal ini selaras dengan argument Habibi (2019) bahwa ilmu pengetahuan berorientasi pada komonikasi dan subjek pendidikan sebagai pusat arah dari pembelajaran. Jika Bahasa Arab harus kiblatnya pada kurikulum Bahasa, karena Bahasa Arab termasuk diantaranya merupakan Bahasa Asing (Hasibuan, 2017). Lebih lanjut pada pada tataran kurikulum 2013 yang lebih mengedepankan pola pikir terapan pembelajaran terhadap siswa dari pada guru yang aktif atau beraksi sebagai pelaku, nah ini sepadan atau sesuai dengan kurikulum yang ada di MA Itmamunnajah.

Padahal menurut sudut pandang kurikulum bahwa Bahasa Arab memiliki empat keterampilan bahasa, yang tidak hanya melulu berorientasi pada keagamaman atau ajaran kepribadian. Tetapi juga penting yang barhubungan dengan aspek kecerdasan otak dan kreativitas kinerja peserta didik yang meliputi (emosi, perasaan, dan kejiwaan mentalnya) (Mahmuddin, and Nur, 2020). 
Serta tindak lanjutnya tumbuhnya pengembangan diri dari siswa yang produktif yang memiliki jiwa pesaing, sabar, rendah hati, menjaga harga diri (selesteem), dan mampu mengendalikan diri atas nafsunya (self-control). Nah di sini sangat tegas untuk ditekankan kepada peserta didik, sebagai bekal yang dominan dan memenuhi potensinya. Pentingnya pendekatan neurolinguistik dalam pembelajaran Bahasa Arab, bagaimana peserta didik bisa mengaplikasikannya baik secara aktif maupun secara gramatikal (Ilfan, 2020). Sebagai suatu kekuatan dan mendampingi para siswa, pendekatan neurolinguistik mampu mengarahkan peserta didik pada target dan tujuan. Siswa didorong dan diarahkan memulai menggunakan akalnya baik otak bagian kanan maupun otak bagian kiri dalam memahami suatu materi didalamnya (Pasiak, 2012).

Berdasarkan bukti yang konkrit, "secara holistic dan universal semua siswa masih mengalami kesulitan lebih-lebih pada siswa kls $X$ (sepuluh). Hal ini biasanya disebabkan oleh karena sebagian siswa dari sekolah umum maupun SMP Negeri berbeda dengan sekolah Madrasah (tsanawiyah) yang sudah dikenalkan dengan percakapan dan mufradat" (3).

Untuk suatu pendekatan dan langkah yang pasti, alternatif yang diambil dengan teori atau metode neurolinguistik, sebagai strategi dan metode yang tepat sasaran atau jitu. Hal ini berdampak dalam penguasaan bahasa asing yang identik Bahasa Arab dapat lebih mudah. Berdasarkan pada kecendrungan para peserta didik, yang sepintas peneliti kupas, bahwa kecenderungan dan kesesuaian dengan minat siswa akan mempengaruhi otak bagian kanan dan otak kiri saling berfungsi dan, akan menimbulkan optimalisasi dalam berpikir kritis sehingga hasilnya mengungkap gudang memori dan bahasa. Karena bahasa itu butuh keseriusan dan diulangulang dalam menyampaikannya, lisan tidak pasif atau kaku.
Berdasarkan bukti hasil penelitian dari informan, bahwa "pada kategori siswa madrasah keseluruhan dari jenjang kls X (sepuluh) hingga kls XII (dua belas) sering terjadi gangguan berbahasa secara linguistik dalam hal fonologi kurang fasih dalam tajwidnya serta penyampaian huruf melalui lisan. Disebabkan otak belum merangsang penuh dalam ujaran bahasa. Dan juga terjadi secara fonologis, artikulasinya cukup bagus dan jelas meskipun sering muncul dalam bermacam-macam penyebutan objek bahasa. Seperti halnya penyampaian dalam tiap-tiap (mufrodat) dan (tarqibul kalimah)" (4). Secara signifikan memang membutuhkan waktu yang efisien dalam mempelajarinya. Alternatif yang jitu tiada lain dengan pendekatan neurolinguistik dalam pembelajaran Bahasa Arab.

Dalam hal ini sesuai dengan fakta yang terjadi pada peserta didik MA itmamunnajah terlihat bahwa kemampuan berkomonikasi ditunjang dengan kecakapan berbahasa. "Kompleksitas bahasa menyesuaikan dan mengikuti akumulasi pemerolehan yang juga saling berkaitan dari yang tingkatan sederhana sampai pada tingkatan yang membutuhkan kemampuan berbahasa dan sosialisasi kepada peserta didik MA Itmamunnajah. Secara psikis kebutuhan peserta diidk MA Itmamunnajah dalam proses belajar meliputi rasa aman, nyaman, kemampuan, kebebasan, kasih saying atau perhatian, kesuksesan dan eksistensinya diakui. Rasa aman dan kasih saying merupakan faktor terpenting dalam ruang likup cakupan pembelajaran Bahasa Arab" (5).

Kemudian untuk dapat merumuskan pengembangan pembelajaran bahasa Arab diperlukan optimalisasi otak kanan dan otak kiri sehingga tidak terdapat masalah dan mendorong keseimbangan dalam memastikan tujuan pembelajaran bahasa Arab, metode pembelajaran Bahasa Arab, teknik pembelajaran Bahasa Arab dan evaluasi pembelajaran Bahasa Arab. Hal sesuai dengan penelitian tentang 
pendekatan neurolinguistik merupakan penekatan yang mengedepankan tentang otak berkaitan dengan bahasa dalam pembelajran. Otak tidak bisa digunakan dalam berucap, karena ada lisan yang sudah bertugas untuk bertindak tutur sedangkan otak adalah sebagai optimalisasi berfikir dalam menyampaikan bunyi atau bahasa (Hilmi, 2017).

\section{Pendekatan Neurolinguistik dalam Pembelajaran Bahasa Arab}

Salah satu organ tubuh manusia yang dapat mengendalikan semua kegiatan secara signifikan adalah otak (Hilmi 2020). Sebuah benda kecil yang beratnya kurang lebih 1,5 kg mempunyai 100 miliar sel saraf yang aktif (neuron) yang dapat memproses konektivitas antara lain: berfikir, merasa, melihat, berbicara, dan mencipta (Brown, and Strawn, 2012). Neuron merupakan bagian fungsi terkecil yang ada pada otak yang bertugas mentrasnsfer sinyal melalui kerja listrik (Ilfan, 2020). Neurolinguistik berasal dari nerusains ilmu yang membahas tuntas tentang otak manusia, fungsi otak dan bagiannya (brain-mindconnection). Hal ini menggambarkan bahwa siswa di sekolah diarahkan asas doktrin yang baik (positif), bahkan mungkin yang selama ini otak rasionalnya atau otak yang berfungsi sebagai penerima sinyal kecerdasan belum terpakai (Suyadi and Widodo, 2019).

Melihat pengalaman dari para guru di MA Itmamunnajah, "bahwa kebanyakan otak para siswa madrasah tidak separah atau tidak terlalu parah buruknya (jahat). Karena sebagian siswa aliyah masih dekat dengan keagamaan (kental dengan kegiatan riyadhoh). Suatu contoh kegiatan keagamaan yang didukung dengan diawali tadarus al-Qur'an, ada respon tersendiri terhadap pengaruh otak" (6).

Bisa disebutkan karena otak sudah dipengaruhi hal-hal yang positif. Secara mendasar pengaruh neurolinguistik terhadap siswa Aliyah akan menjadi refleksi neuro-anatomi otak (struktur otak) dan neurofiologi otak (bagian atau tugas masing-masing otak) yang memberikan kemanfaatan transfer knowledge secara sikap dan rasional (Nasution, 2017). Berdasarkan bukti pendekatan neurolinguistik "karakteristik dari aplikasi neurolinguistik sebagai pendekatan pembelajaran dalam Bahasa Arab merupakan pendekatan pembelajaran yang holistik pada fungsi otak. Mengatur dan mengendalikan bahasa termasuk mengendalikan perilaku siswa yang paling primitif serta bertanggung jawab secara komprehensif terhadap aktivitas yang melibatkan pikiran, emosi dan perasaan" (7). Ilfan (2020) mengklasifikasikan karakteristik neurolinguistik dalam pengembangan pembelajaran Bahasa Arab yaitu: multiple intellegence, emotional intellegence, spritual intellegence, adversity quotient, brain based learning, and instrumentasi.

Hasil riset perkembangan neurosains dengan linguistik pada pembelajaran Bahasa Arab di MA Itmamunnajah, "melahirkan proses sikap kepribadian yang tidak hanya pada tanggap-rangsangan, akan tetapi juga memanfaatkan mekanisme biologis yang dapat melihat cara kerja otak para peserta didik (living brain) dengan mempelajarinya secara seksama" (8). Sebagaimana yang diketahui hasil riset tersebut diteliti dengan teknologi mutakhir yang super canggih seperti PET (Passitron Emisson Tongraphy), SPECT (Single-Photon Emission Computerized Tomography), FMRI (Fungsional Magnetic Resonance Imaging) (Suyadi, et al. 2019). Berdasarkan data lapangan "dilihat dari basis kegiatan pendidik dalam pembelajaran bahasa Arab, system saraf otak adalah bagian yang paling dominan dalam mengaktualisasikan kerangka berfikr dan menangkap informasi dalam aktivasi bahasa. Tidak diragukan lagi bahwa neurolinguistik dalam desain pembelajaran Bahasa Arab cukup pesat perkembangannya dari masa kemasa" (9). Secara fakta bukti peran neurlinguistik dalam pembelajaran adalah optimalisasi 
otak sebagai reflektivitas dalam tanggaprespon bahasa.

Di Amerika, pendekatan neurolinguistik bukan lagi disiplin ilmu tetapi juga berperan penting dalam pendidikan secara spesifik terhadap pembelajaran. Hal itu karena tujuan pendidikan yang tergantung pada objek yaitu peserta didik. Sedangkan potensi peserta didik bertumpu pada cara kerja otaknya (Shalihin, et al. 2021). Suyadi (2016) dalam bukunya menyebutkan tiga tahapan peran neurosains sangat berhubungan dengan neurolinguistik dalam aspek teori pendidikan Islam adalah; (1) merespon dan menyimpan informasi; (2) mengembangkan informasi menjadi ide waawasan yang baru; dan (3) mengaplikasikan ide dalam mengatasi masalah.

Implikasi neurolinguistik dalam pembelajaran Bahasa Arab di MA Itmamunnajah "dapat dimaksimalkan melalui optimalisasi penggunaan cara kerja otak kanan dan otak kiri. Dimana optimalisasi otak pada peserta didik memberi rangsangan pada semua system saraf dan sel saraf untuk melibatkan secara bersamaan dalam memaunculkan suatu target dan hasil yang sungguhsungguh dalam pembelajaran Bahasa Arab, yang diantaranya melibatkan, rasional, emosional, perasaan, kejiwaan, dan spiritual" (10).

Pengembangan

pembelajaran pembelajaran Bahasa Arab dari suatu masa kemasa yang lain dinilai sangat penting kemanfaatannya, serta dibuktikan masih menerima konstruksi pemikiran model pembelajaran yang baru dan relevan sesuai desain pembelajaran bahasa Arab masa kini yang berimplikasi pada otak. Hal itu terjadi disebabkan rancangan dan perencanaan pembelajaran bahasa Arab masih bersifat teacing Arabic language (pembelajaran bahasa Arab) bukan teaching about Arabic language (mengajarkan tentang bahasa Arab) (Yunita, and Pebrian, 2020). Hal ini menggambarkan bahwa pendekatan neurolinguistik merupakan fungsi dari pada pengembangan pembelajaran Bahasa Arab. Memiliki fungsi pemberian pedoman pengembangan pembelajaran, diantaranya jenis, ruang lingkup, dan urutan isi pembelajaran dalam proses pendidikan.

Dengan demikian, pendekatan neurolinguistik sangat sentral dalam penerapannya pada kegiatan pembelajaran Bahasa Arab di kelas. Di luar dari aspek materi, perumusan pembelajaran Bahasa Arab harus memperhatikan kepentingan peserta didik sesuai kemampuannya dengan cara pendekatan riset terlebih dahulu (prior research). Tindakan yang mumpuni sesuai kriteria silabus dan kurikulum adalah tindakan psikologi pendidikan peserta didik yang sangat dibutuhkan dalam menerapkan suatu metode dan pendekatan pembelajaran (Tambak et al. 2020). Menurut Schiller (2020) dalam kajian ilmu neurosains pendidikan, guru bukanlah satu-satunya ahli dalam bidang otak. Melainkan guru adalah salah satu profesi yang mempengaruhi dan merubah otak.

Suyadi, and Widodo (2019) menjelaskan bahwa peserta didik pada umumnya baru menggunakan 5-8 persen potensi otak dan 10-15 persen penggunaaan otak dalam ruang lingkup lembaga pendidikan. Rumusan pendidikan dalam proses pembelajaran tidak lepas dari peranan otak yang memiliki makna penting dari segi nafs, qalb, dan ar-rub. Dengan demikian, hakikat sejatinya pembelajaran perspektif Islam dalam pembelajaran Bahasa Arab yaitu mencetak insan kamil yang meliputi unsur jasmani, rohani, dan akal; IQ/EQ/SQ; serta aspek kognitif, afektif, dan psikomotorik.

Data dari informan di MA Itmamunnajah menunjukkan bahwa "aktivitas pembelajaran Bahasa Arab dimulai dari potensi fitrah peserta didik sebagai makhluk hidup yaitu sistem saraf otak (neurosains). Sistem saraf dibekali dan dipengaruhi oleh landasan perilaku 
pendidikan dan landasan pendidikan karakter yang berperan pada aspek kognitif yang berkaitan dengan pengetahuan dasar bahasa Arab dan psikomotorik yang berhubungan dengan keterampilan dalam berbahasa Arab. Demikian pula landasan psikologis yang berperan penuh terhadap aspek afektif yang mengelola pada nilai-nilai perilaku, karakter, emosi, perasaan, dan jiwa" (11). Tugas kerja lain dari landasan psikologi dan edukatif adalah mempersatukan peranan penting otak kanan dan otak kiri dalam sebuah perkembangan emosional quotient (EQ), kemampuan intuitif, dan interaksi belajar serta pengesahan kemampuan logika dalam fasih membaca dan menulis Bahasa Arab. Kedua landasan tersebut berkaitan dan terintegrasi dalam komponen pengembangan pembelajaran Bahasa Arab (Abdullah, and Masruri, 2019; Tambak, et al. 2020). Peranan penting pendekatan neurolinguistik dalam otak peserta didik meliputi, tujuan metode, dan strategi pembelajaran dapat menghasilkan karya cipta neurosain dalam diskursus pendekatan pembelajaran Bahasa Arab.

Metodik ditaktik neurolinguistik, sebelum guru mengenalkan pembelajaran Bahasa Arab melalui pendekatan neurolinguistik, sebaiknya mengukur kecendrungan peserta didik: Apakah peserta didik sudah merespon atau sudah siap menerima dalam belajar Bahasa Arab. Termasuk pemilihan materi dalam pembelajaran juga harus disesuaikan dengan antusias pelajar, apalagi pada kelas sekolah formal non ma'had biasanya sangat sulit untuk langsung mengerti. Pada siswa dapat dipilih tema-tema yang sangat menarik sesuai bakat minat mereka. Hal lain mungkin yang lebih diperhatikan pendidik harus paham tingkat kemampuan peserta didiknya, misal jika masih kelas $\mathrm{X}$ (sepuluh) madrasah jangan langsung dijastifikasi diberi materi tentang (alfiyah). Alangkah baiknya jika deberi materi bab (alamatil i'rob) (Mutia, Gimin, and Mahdum, 2020). Dengan hal itu lebih mudah dalam menerapkan sistem pembelajaran neurolinguistik, dengan pendekatan secara nalar pada akal dan bahasa sebagai hasil akhirnya (Miftakhuddin, 2020).

\section{Evaluasi Pendekatan Neurolinguistik}

Semua guru dalam menggunakan pendekatan neurolinguistik dalam pembelajaran dan melaksanakan proses evaluasi berkesinambungan. "Kami diperintahkan oleh kepala madrasah untuk menyiapkan instrumen dalam proses assessment pendekatan neurolinguistik yang kami terapkan. Hal ini dimaksudkan untuk mengukur ketercapaian pendekatan yang dilakukan dan sekaligus memberikan tindak lanjut perbaikan di masa yang akan datang" (3).

Dalam melaksanakan tujuan pembelajaran Bahasa Arab "diperlukan pemilihan atau penyusunan bahan ajar yang tepat dan sesuai dengan tujuannya. Setelah bahan ajar tersusun dengan baik, maka langkah selanjutnya adalah memilih metode (strategi dan teknik) dalam implementasinya serta jika diperlukan menggunakan media yang berfungsi mendukung pelaksanaan pembelajaran. Pandangan akhir yang mengukur apakah implementasi berjalan dengan baik sesuai dengan tujuan yang diharapkan, maka dilakukan evaluasi terkadang dilakukan pada tengah dan akhir semester, bahkan baik juga dilakukan evaluasi pada setiap akhir materi pembelajaran bahasa Arab agar dapat termonitor dengan baik" (4).

Sebuah proses penerapan kurikulum pendidikan dalam pengembangan pembelajaran Bahasa Arab dari sebuah proses alur perjalanan yang telah dirancang dan disusun dengan sedemikian bagusnya tidak bisa dipisahkan dari sebuah evaluasi pembelajaran (Ismail, 2013). Evaluasi pembelajaran sebagai pengukur berhasil tidaknya atau tercapainya sebuah target tujuan pembelajaran Bahasa Arab, baik digunakan dalam rangkaian struktur organisatoris kebijakan kurikulum pendidikan maupun para peserta didik. Hal ini dilakukan pada peserta didik untuk 
dapat terus menerus berkarya mengembangkan kemampuan dirinya berkriatif dan inovatif sesuai dengan cara kerja otak dalam belajar Bahasa Arab (Yunita, and Pebrian, 2020; Ahmad, and Tambak, 2018). Evaluasi pembelajaran Bahasa Arab dengan pendekatan neurolinguistik menggunakan evaluasi cara kerja otak pada lobus frontal sebagai neurobiologis kekuatan akal pada peserta didik. Hal ini bersama lisan dalam keterlibatan percakapan komonikasi bahasa, yang mempengaruhi hasil belajar peserta didik (Jailani, Suyadi, and Djabedi, 2021; Sukenti, Tambak, and Charlina, 2020). Baik dari perencanaan, perancangan, sampai aplikasi praktek bahasa secara totalitas dari organisasi kurikulum Bahasa Arab yang telah diimplementasikan terhadap semua peserta didik (Jailani, et al. 2021; Tambak, 2014). Evaluasi menurut Tu'aimah (2000) merupakan kumpulan teknik pembelajaran yang digunakan untuk mendapatkan dan mengumpulkan hasil pembelajaran yang berlangsung atau yang akan dilaksanakan.

\section{PENUTUP}

Hasil penelitian ini menemukan bahwa pendekatan neurolinguistik dalam pengembangan pembelajaran bahasa Arab di MA Itmamunnajah mampu mengkonstruk pemahaman para peserta didik dalam belajar bahasa Arab. Sesuai dengan fungsi otak yang bekerja sebagai penerima sinyal dan informasi dalam belajar bahasa Arab. Sehingga otak lebih signifikan merespon materi-materi pembelajaran yang disampaikan oleh pendidik. Hal ini terjadi karena neurolinguistik, mempengaruhi kesesuaian kerja otak pada peserta didik dalam belajar bahasa. Bisa disebutkan antara struktur bagian otak depan (lobus frontal) dan respon terhadap lisan menghasilkan transfer-transfer knowledge dalam ujaran (cakap) bahasa. Pola pikir peserta didik melibatkan system saraf pada otaknya yang berperan sesuai cara kerjanya, untuk memberikan gambaran objek dan analisis sehingga para peserta didik mudah kreatif dan inovatif dalam mengelola pembelajaran. Pendekatan neurolinguistik sebagai desain pembelajaran bahasa Arab yang modern sangat berperan penting terhadap peningkatan otak pada bahasa, yang meliputi dalam aspek afektif kemampuan dalam (menulis dan membaca bahasa Arab), serta aspek psikomotorik yang berhubungan dengan kemampuan (keterampilan praktek percakapan berbahasa Arab), sebagaimana yang sering diterapkan oleh pendidik dalam pembelajaran Bahasa Arab. Mengoptimalkan dan menintegrasikan cara kerja otak dalam belajar bahasa yang bertujuan agar peserta didik lebih mandiri dan dapat mengembangkan hasil kemampuan belajarnya, baik secara belajar aktif percakapan (muhadatsah) maupun secara pasif tata bahasa (quwa'idul arabiyah).

Hasil penelitian ini berimplikasi luas terhadap diskursus pembelajaran bahasa Arab di masa revolusi indsutri 4.0, terlebih pada masa pandemi COVID-19 saat ini. Peneliti merekomendasi kepada akedemisi, peneliti, praktisi, guru dan lembaga pendidikan formal dan pondok pesantren, untuk dilakukan penelitian lanjutan guna menemukan model pembelajaran bahasa Arab yang komprehensif. Penelitian tentang pembelajaran bahasa Arab berbasis tafsir yang semua materi berkaitan dengan ayatayat Al-Qur'an dalam rangka mendekatkan peserta didik kepada AlQur'an. Di samping itu penelitian yang mengkonstruk pendekatan akal bertingkat Ibnu Sina, karena peneliti menyadari belum ada peneliti yang mengarah dalam basis penelitian tersebut. 


\section{DAFTAR RUJUKAN}

Azis Abdullah, Siswanto Masruri, Khoiruddin Bashori. "Islamic Education and Human Construction in the Quran, International Journal of Education and Learning 1." International Journal of Education and Learning 1.1 (2019): 27-32.

Ahmad, Muhammad Yusuf, Syahraini Tambak, and Uswatun Hasanah. "Pengaruh Kecerdasan Emosional terhadap Penyesuaian Diri Mahasiswa Thailand." Al-Hikmah: Jurnal Agama dan Ilmu Pengetahuan 15.2 (2018): 16-30. https://doi.org/10.25299/al-

hikmah:jaip.2018.vol15(2).2374.

Ahmad, Muhammad Yusuf, and Syahraini Tambak. "Penanaman Nilai-Nilai Pendidikan Akidah Melalui Mata Pelajaran Sejarah Kebudayaan Islam (SKI)." Al-Hikmah: Jurnal Agama dan Ilmu Pengetahuan 15.1 (2018): 24-41. https://doi.org/10.25299/jaip.2018. vol15(1).1581.

Ahmad, Muhammad Yusuf, Syahraini Tambak, and Mira Syafitri. "Etika Pergaulan Islami Santri Madrasah Aliyah (MA) di Pesantren Jabal Nur Kecamatan Kandis Kabupaten Siak." Al-Hikmah: Jurnal Agama dan Ilmu Pengetahuan 13.2 (2016): 206-226. https://doi.org/10.25299/al-

hikmah:jaip.2016.vol13(2).1524.

Ahmad, Mawardi. "Hubungan Potensi Akal dengan Kreativitas Belajar Siswa Bidang Studi Pendidikan Agama Islam di SMK Kanada Sakura Indonesia (KANSAI) Pekanbaru." Jurnal Pendidikan Agama Islam AlThariqah 2.1 (2017): 51-72. https://doi.org/10.25299/althariqah. 2017.vol2(1).647.

Ahmad, Mawardi, and Syahraini Tambak. "Penerapan Metode Diskusi Dalam Meningkatkan Hasil Belajar Murid Pada Pelajaran Fiqh." Al-Hikmah: Jurnal Agama Dan Ilmu Pengetahuan 15.1 (2018): 64-84. https://doi.org/10.25299/jaip.2018. vol15(1).1585.
Beatty-Martínez, Anne L., and Paola E. Dussias. "Revisiting Masculine and Feminine Grammatical Gender in Spanish: Linguistic, Psycholinguistic, and Neurolinguistic Evidence." Frontiers in Psychology 10 (2019): 236-241.

Fauzi Muhammad Ilfan. "Pemanfaan Neurosains Dalam Desain Pengembangan Kurikulum Bahasa Arab." Arabiyatuna: Jurnal Bahasa Arab 4.1 (2020): 1-12.

Ferretti, Todd R. et al. "How Discourse Constraints Influence Neurolinguistic Mechanisms during the Comprehension of Proverbs." Cognitive, Affective and Behavioral Neuroscience 20.3 (2020): 14-23.

Habibi, Burhan Yusuf. "Integrasi Kurikulum Bahasa Arab Pesantren Tradisional Dan Modern Di Madrasah Aliyah Program Keagamaan." Journal of Arabic Studies: (2019): 161.

Hamzah, Desi Sukenti, Syahraini Tambak, and Wisudatul Ummi Tanjung. "Overcoming self-confidence of Islamic religious education students: The influence of personal learning model." Journal of Education and Learning (EduLearn) 14.4 (2020): 582-589.

https://doi.org/10.11591/edulearn.v 14i4.16759.

Hamzah, Hamzah, Syahraini Tambak, and Nella Ariyani. "Upaya Guru Pendidikan Agama Islam dalam Pembentukan Kepribadian Islam Siswa di SMA Negeri 2 Kelayang Kabupaten Indragiri Hulu." AlHikmah: Jurnal Agama dan Ilmu Pengetahuan 14.1 (2017): 76-95. https://doi.org/10.25299/alhikmah:jaip.2017.vol14(1).1528.

Hilmi, Danial. "Sistem Pembelajaran AlQawa'id AlSharfiyah Di Indonesia Dalam Perspektif Neurolinguistik." Tarbiyatuna 2.1 (2017): 40-68.

Hilmi, Danial. "Impact Of Arabic Online Learning In The Perspective Of How The Brain Learns." Ijaz Arabi Journal of Arabic Learning 4.1 (2020): 59-73. 
Iljina, Olga et al. "Neurolinguistic and Machine-Learning Perspectives on Direct Speech BCIs for Restoration of Naturalistic Communication." BrainComputer Interfaces 4.3 (2017): 186199.

https://doi.org/10.1080/2326263X.2 017.1330611.

Jailani, Mohammad et al. "Pengembangan Materi Pembelajaran Pendidikan Agama Islam: Implikasinya Terhadap Pendidikan Islam." Al-Idarah: Jurnal Kependidikan Islam 11.1 (2021): 4355.

Jailani, Mohammad, Suyadi, and Dedi Djabedi. "Menelusuri Jejak Otak dan 'Aql dalam Al-Qur'an Perspektif Neurosains dan Pendidikan Islam Di Era Pandemi COVID-19." Tadris: Jurnal Pendidikan Islam 16.1 (2021): 1-19.

Jundi, Muhammad, and Zohra Yasin. "Penilaian Sejawat Dalam Pembelajaran Keterampilan Dasar Mengajar Bagi Mahasiswa Pendidikan Bahasa Arab Pada Mata Kuliah Pembelajaran Mikro." Maharat: Jurnal Pendidikan Bahasa Arab 2.2 (2020): 51-70.

Kharisma Noor Latifatul Mahmudah, Suyadi. "Akal Bertingkat Ibnu Sina Dan Taksonomi Bloom Dalam Pendidikan Islam Perspektif Neurosains." Edukasi Islamika: Jurnal Pendidikan Islam 5.1 (2020): 21-38.

Lias Hasibuan. Kurikulum Dan Pemikiran Pendidikan. Jakarta: Gaung Persada. 2017.

Mochamad Ismail. "Peranan Psikolinguistik Dalam Pembelajaran Bahasa Arab." At-Ta'dib 8.2 (2013): 178-189.

Muhammad Miftakhuddin. "Pengembangan Model Pendidikan Agama Islam Dalam Membentuk Karakter Empati Pada Generasi Z." JPAI: Jurnal Pendidikan Agama Islam 17.1 (2020): 1-16.

Mutia, Lilis, Gimin Gimin, and Mahdum Mahdum. "Development of Blog-
Based Audio Visual Learning Media to Improve Student Learning Interests in Money and Banking Topic." Journal of Educational Sciences 4.2 (2020): 436.

Noer, Ali, Syahraini Tambak, and Harun Rahman. "Upaya Ekstrakurikuler Kerohanian Islam (ROHIS) dalam Meningkatkan Sikap Keberagamaan Siswa di SMK Ibnu Taimiyah Pekanbaru." Jurnal Pendidikan Agama Islam Al-Thariqah 2.1 (2017): 21-38. https://doi.org/10.25299/althariqah. 2017.vol2(1).645.

Ronny Mahmuddin, and Chamdar Nur. "Teknik Pembelajaran Ilmu Nahwu Berdasarkan Teori Integrasi." NUKHBATUL 'ULUM: Jurnal Bidang Kajian Islam 6.1 (2020): 36-44.

Rusdy Tu'aimah. Marjak Fi Ta'limil Lughoh Al Arabiyah Linnaatiqiin Bi Lughotin Ukhro.

Sahkholid Nasution. Pengantar Linguistik Bahasa Arab. Pertama. ed. Mohammad Kholison. Siduarjo Jawa timur: CV. Lisan Arabi. 2017.

Schiller, Niels 0 . "Neurolinguistic Approaches in Morphology." Oxford Research Encyclopedia of Linguistics (2020): 1-23.

Shalihin, Rahmat Ryadhush, Suyadi, Desfa Yusmaliana, and Diyan Faturahman. "Rational Brain Transmutation Into Intuitive Brain Based on Neuroscience in Islamic Education." In Rational Brain Transmutation Into Intuitive Brain Based on Neuroscience in Islamic Education, Bukittinggi, Indonesia: BICED, IAIN Bukittinggi. (2021): 1-10.

Sitohang, Kusmadi.. "Pengembangan Metode Pemrograman Neurolinguistik Berbantuan Literasi Informasi Dalam Pembelajaran Berpidato Siswa Sekolah Menengah Atas." Universitas Pendidikan Indonesia. 2019a

Sukenti, Desi, and Syahraini Tambak. "Developing Indonesian Language Learning Assessments: Strengthening 
the Personal Competence and Islamic Psychosocial of Teachers." International Journal of Evaluation and Research in Education 9.4 (2020): 1079-1087.

Sukenti, Desi, and Syahraini Tambak. "Strengthening Islamic Psychosocial and Self-confidence in Develophing Student Thinking Creative." ICOSEEH 20194 (2019): 446-453.

Suyadi. 2016. Teori Pembelajaran Anak Usia Dini Dalam Kajian Neurosains. pertama. Bandung: Remaja Rosdakarya.

Suyadi. "Constitutional Piety: The Integration of Anti-Corruption Education into Islamic Religious Learning Based on Neuroscience." Jurnal Pendidikan Agama Islam 6.1 (2019): 38-46. http://ejournal.uinmalang.ac.id/index.php/jpai.

Suyadi. "Immunology Pedagogical Psychology of Pesantren Kindergarten: Multicase Study at Pesantren Kindergarten in Yogyakarta." Addin 13.1 (2019): 57. https://doi.org/10.21043/addin.v13i 1.3510 .

Suyadi, Zalik Nuryana, and Niki Alma Febriana Fauzi. "The Fiqh of Disaster: The Mitigation of Covid-19 in the Perspective of Islamic EducationNeuroscience." International Journal of Disaster Risk Reduction 51.2 (2020): 1-15. https://doi.org/10/1016/J.ijdrr.2020 .101848 .

Suyadi, and Hendro Widodo. "Millennialization of Islamic Education Based On Neuroscience In The Third Generation University In Yogyakarta Indonesia." QIJIS: Qudus International Journal of Islamic Studies 7.1 (2019): 173-202.

Tambak, Syahraini, Mawardi Ahmad, Desi Sukenti, and Abd. Rahman bin Abd. Ghani. "Profesionalisme Guru Madrasah: Internalisasi Nilai Islam Dalam Mengembangkan Akhlak Aktual Siswa." Jurnal Pendidikan Agama Islam Al - Thariqah 5.2 (2020):
79-96.

DOI:

https://doi.org/10.25299/al-

thariqah.2020.vol5(2).5885.

Tambak, Syahraini, Muhammad Ali Noer, Siti Humairoh, and Mawardi Ahmad. "Internalization of Riau Malay Culture in Developing the Morals of Madrasah Ibtidaiyah Students." Al Ibtida: Jurnal Pendidikan Guru MI 7.1 (2020): 6984.

Tambak, Syahraini, and Desi Sukenti. "Strengthening Islamic behavior and Islamic psychosocial in developing professional madrasah teachers." Cakrawala Pendidikan: Jurnal Ilmiah Pendidikan 39.1 (2020): 65-78.

Tambak, Syahraini. "Pendidikan Etika Bergaul Islami Dalam Keluarga "Nilai Pendidikan Etika Berlaku Adil Orangtua dengan Anak dalam Pergaulan Keluarga Perspektif Hadits"." Jurnal Pendidikan Agama Islam Al-Thariqah 4.1 (2019): 1-20. https://doi.org/10.25299/althariqah.2019.vol4(1).2910.

Tambak, Syahraini, M. Yusuf Ahmad, and Desi Sukenti. "Strengthening Emotional Intelligence in Developing the Madrasah Teachers' Professionalism (Penguatan Kecerdasan Emosional dalam Mengembangkan Profesionalisme Guru Madrasah)." Akademika 90.2 (2020).

https://doi.org/10.17576/akad2020-9002-03.

Tambak, Syahraini, and Desi Sukenti. "Pengembangan profesionalisme guru madrasah dengan penguatan konsep khalifah." Hayula: Indonesian Journal of Multidisciplinary Islamic Studies 4.1 (2020): 41-66. https://doi.org/10.21009/004.01.0.

Tambak, Syahraini, Amril M, Zuriatul Khairi, and Desi Sukenti. "Development of Madrasah Teacher Professionalism by Strengthening the Khalifah Concept and Islamic Psychosocial Perspective." International Conference on Islamic Education (ICIE 2018). Atlantis Press, 
2018. https://doi.org/10.2991/icie18.2018.7.

Tambak, Syahraini, et al. "Exploring Malay Culture in Madrasah Learning: Revealing the Value of Malayness in Madrasah Tsanawiyah Curriculum." Madania: Jurnal Ilmu-Ilmu Keislaman 10.2 (2020): 87-104.

Tambak, Syahraini. "Jihad Pendidikan: Konsep dan Upaya Memajukan Pendidikan Indonesia." Al-Hikmah 7.14 (2010): 1-15.

Tambak, Syahraini. "Filsafat Idealisme dan Implikasinya pada Teori Pendidikan." Al-Hikmah 11.1 (2014): 61-75.

Taufik Pasiak. Brain Based Learning Merupakan Teknik-Teknik Pembelajaran Yang Mengacu Pada Kerja Otak Dengan Mengelola Gaya Belajar, Mengolah Informasi, Pola Respon Dan Penggunaan Imajinasi. Bandung: PT Mizan Pustak. 2012.

Tri Budianingsih. "Peran Neurolinguistik Dalam Pengajaran Bahasa." Al-Azhar Indonesia Seri Humaniora 3.2 (2015): 37-49.
Vogel, Stephan E., Celia Goffin, and Daniel Ansari. "Developmental Specialization of the Left Parietal Cortex for the Semantic Representation of Arabic Numerals: An FMR-Adaptation Study." Developmental Cognitive Neuroscience 12.1 (2015): 61-73. http://dx.doi.org/10.1016/j.dcn.201 4.12.001.

Warren S. Brown and Brad D. Strawn. The Physical Nature of Christian Life: Neuroscience, Psychology, and the Church. New York: Cambridge University Press. 2012.

Winarto, Winarto, Ahmad Syahid, and Fatimah Saguni. "Effectiveness the Use of Audio Visual Media in Teaching Islamic Religious Education." International Journal of Contemporary Islamic Education 2.1 (2020.): 81-107.

Yunita, Yenni, and Rojja Pebrian. "Metode Komunikatif Dalam Pembelajaran Bahasa Arab Maharah Al-Kalam Di Kelas Bahasa Center for Languages and Academic Development." Jurnal Pendidikan Agama Islam Al-Thariqah 5.2 (2020): 56-63. 